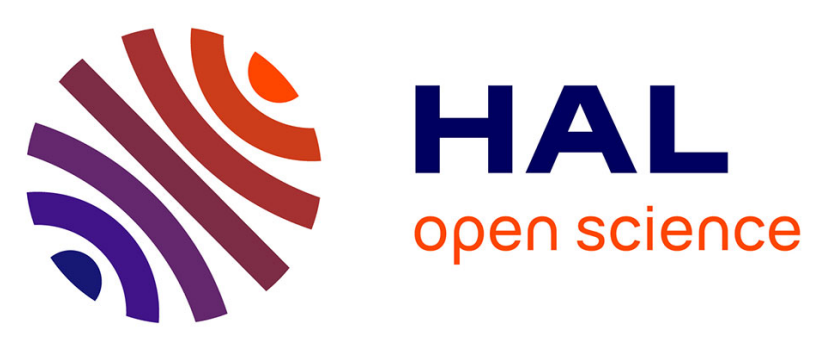

\title{
Intermediate filaments against actomyosin: the david and goliath of cell migration
}

Emma J van Bodegraven, Sandrine Etienne-Manneville

\section{To cite this version:}

Emma J van Bodegraven, Sandrine Etienne-Manneville. Intermediate filaments against actomyosin: the david and goliath of cell migration. Current Opinion in Cell Biology, 2020, 66, pp.79-88. 10.1016/j.ceb.2020.05.006 . pasteur-02918356

\section{HAL Id: pasteur-02918356 \\ https://hal-pasteur.archives-ouvertes.fr/pasteur-02918356}

Submitted on 7 Jan 2021

HAL is a multi-disciplinary open access archive for the deposit and dissemination of scientific research documents, whether they are published or not. The documents may come from teaching and research institutions in France or abroad, or from public or private research centers.
L'archive ouverte pluridisciplinaire HAL, est destinée au dépôt et à la diffusion de documents scientifiques de niveau recherche, publiés ou non, émanant des établissements d'enseignement et de recherche français ou étrangers, des laboratoires publics ou privés. 


\section{Intermediate filaments against acto-myosin: the David and Goliath of cell migration}

Emma J.van Bodegraven, Sandrine Etienne-Manneville*

Cell Polarity, Migration and Cancer Unit, Institut Pasteur, UMR3691 CNRS, Equipe Labellisée Ligue Contre le Cancer, F-75015, Paris, France.

*Correspondence: setienne@pasteur.fr

Word count: 3059

\section{Abstract}

Intermediate filaments (IFs), together with actin and microtubules, constitute the cytoskeleton and regulate essential biological processes including cell migration. Despite the well-described changes in the composition of IFs in migrating cells, the mechanism by which these changes may contribute to cell migration remains elusive. Recent studies show that IFs control cell migration by impacting the acto-myosin machinery. This review discusses how the unique physical properties of IFs, the interplay between IFs and the acto-myosin network, and the connection of IFs with cell adhesive structures participate in cell migration. We highlight the biochemical and mechanical mechanisms by which IFs control acto-myosin generated forces to influence migration speed and contribute to nuclear integrity and cell resilience to compressive forces in 2D, as well as in confined 3D migration.

\section{Introduction}

Intermediate filaments (IFs) are $10 \mathrm{~nm}$ diameter filaments composed of homo- or heteropolymers of IF proteins which are encoded by a large family of 70 different genes. They extend throughout the cytoplasm, connect cortical cell structures to intracellular organelles such as the nucleus, and are involved in a wide range of biological processes [1-3] including cell migration [4-7].

Most in-depth studies on cell migration have focused on the actin cytoskeleton. These studies have highlighted the key role of actin in generating forces that are essential for cell migration $[8,9]$. Actin polymerization and actomyosin contraction regulate the formation of protrusions, traction forces and rear retraction and enable forward cell movement. The multiple and essential mechanical functions of the acto-myosin network as well as its recently demonstrated ability to adjust to the 
physical properties of the microenvironment [10] have pointed to the actin cytoskeleton as a mastermind of cell migration. However, evidence for the rearrangement of the microtubule and IF network during migration have progressively emerged, suggesting that the three cytoskeletal structures cooperate to control cell migration $[4,5,11,12]$. The engagement of microtubules in mesenchymal migration has been proven by their contribution to cell polarization, formation of cell protrusions, and the turnover of focal adhesions (FAs) [12-15]. The role of IFs in cell migration has long remained elusive despite well-described changes in IF expression that contribute to cell migratory properties [6]. The best example is the upregulation of vimentin upon epithelial-to-mesenchymal transition (EMT) $[16,17]$. Accordingly, many different studies have indicated that cell migration is impacted by the loss of IFs although the net effect on migration depends on the cell and IF protein types [5,18-22]. The dynamic regulation of IFs is still poorly understood and the major question that remains is how IFs, despite lacking molecular motors and not being intrinsically polarized, participate in cell migration.

IFs may impact cell migration through their interaction with actin and microtubules via cytoskeletal linker-proteins such as plectin and Adenomatous Polyposis Coli (APC) [23-30]. Alternatively, IFs can serve as a platform for signaling pathways that are important for cell migration $[4,31]$. Finally, IF-influence on cell migration may involve their unique physical properties._Following these hypotheses, the impact of IFs on cell mechanics and on the acto-myosin machinery has gained in-depth attention over the recent years. This review will highlight the intrinsic mechanical properties of IFs and their dynamic interplay between the acto-myosin machinery and the IF network. It will discuss how the mechanical and signaling properties of IFs enable them to control the amplitude and the distribution of forces during migration and provide resistance to compressive forces in a confined 3D environment.

\section{IFs impact cell mechanical properties}

Compared to actin and microtubules, single IFs are extremely resistant to breakage, can be stretched more than 3-fold [32,33], and have been shown to undergo strain-stiffening [34,35]. Force-strain curves obtained from optically trapped filaments show a steep linear increase in filament stiffness at low strains, which is attributed to the elastic stretching of $\alpha$-helices. Then, the force remains equal while strain increases. The uncoiling of $\alpha$-helices into $\beta$-sheets is thought to be responsible for this observation which reflects the ability of IFs to absorb energy [34,35]. Single vimentin filaments are able to dissipate more then $70 \%$ of the input energy as measured by the cyclic stretching and relaxation of filaments [36]. At large strains, a strong increase in stiffening is observed which is likely to result from increased pulling on the $\beta$-sheets [34,35]. Vimentin networks also display elastic and strain-stiffening properties [37]. Compared to actin, vimentin networks are highly elastic. However, their elasticity 
decreases when actin is mixed in the composite network. At low strains, the actin network stiffens while vimentin softens, attributed to slippage of polymers. At high strains when the actin network softens due to fluidization, the vimentin network stiffens by the unfolding of filaments [37]. In cells, IF's mechanical characteristics have shown to contribute to the cells ability to withstand large deformations [38] and propagate local deformations throughout the cytoplasm to prevent damage [39]. During cell migration, these physical properties of IFs may allow them to take up the energy generated by actomyosin-generated forces.

\section{IFs tame the force-generating acto-myosin machinery}

There are several ways by which the acto-myosin cytoskeleton affects the composition of the IF network [4]. For example, decreasing acto-myosin contractility decreases keratin IF node dynamics in SW13 cells [40] and keratin localizes towards cell-cell adhesions of embryonic mesendoderm cells upon the application of local tensions [41]. In addition, the solubility of vimentin, indicative of filament disassembly, is increased in human mesenchymal stem cells on soft substrates compared to stiff substrates and upon inhibition of acto-myosin assembly [42]. Conversely, although the exact mechanism often remains eften unknown, changes in the IF network influence cellular forces and the force-generating capacity of the acto-myosin machinery [19,22,43-45]. IFs direct- or indirectly interact with actin via cytoskeletal linkers such as plectins $[23-26,26-28,46,47]$ and modulate RhoA activity, a RhoGTPase which directly promotes the formation of acto-myosin stress fibers and cell contractility. In osteosarcoma cells, vimentin IFs inhibit RhoA by binding to the guanine-exchange-factor GEF-H1 [48] and in MDCK cells, keratin 18 activates RhoA via another RhoA-GEF, i.e. Solo [49].

During collective migration of cell sheets two different types of actin fibers are observed; longitudinal stress fibers which are anchored at FAs at the front of leader cells and extend towards the rear of the cell and interjunctional transverse arcs anchored at adherens junctions (AJs) which connect the lateral sides of adjacent cells. These structures are engaged in a continuous retrograde flow, organized by the movement of myosin motors along stress fibers [50-52]. High traction forces are generated at the front of leader cells. These forces contribute to the migration of leaders and are transmitted to follower cells by adherens junctions [53-56]. Two recent studies indicate that during collective cell migration IFs influence the generation and the distribution of forces by the direct or indirect interaction with the acto-myosin machinery (Figure 1).

In collectively migrating astrocytes depletion of vimentin, glial fibrillary acidic protein (GFAP), and nestin decreases migration speed, persistence, and directionality [57], accompanied by a drastic change in the actin organization (Figure 1A). In IF-depleted cells, longitudinal stress fibers are more 
pronounced and interjunctional transverse arcs are rarely observed. In parallel, the amplitude and distribution of traction forces is altered. Instead of concentrated forces at the cell front, traction forces are exerted through FAs at the front, center, and back of IF-depleted cells. Moreover, depletion of IF proteins increases traction forces in follower cells resulting in similar traction forces exerted by leader and follower cells [57]. Overall, the loss of IFs increases forces throughout the migrating monolayer. Plectin depletion mimics the migratory phenotype of IF depleted astrocytes, supporting the hypothesis that IFs regulate cell migration and traction forces through an interaction with the acto-myosin force generating machinery [57].

An interaction of keratin 6 with myosin IIA, the molecular motor responsible for acto-myosin contractility, has been described in collectively migrating keratinocytes (Figure 1B). Keratin 6a and 6b (K6a/b) null mice show impaired epithelization and blistering [58] and in keratinocyte explants of $\mathrm{K} 6 \mathrm{a} / \mathrm{b}$ null mice cell migration upon skin injury is enhanced [59]. This suggests that the upregulation of $\mathrm{K} 6 \mathrm{a} / \mathrm{b}$, which is normally observed following skin injury, attenuates keratinocyte migration. The attenuation of migration is needed to ensure collective keratinocyte migration and re-epithelization. The impact of $\mathrm{K} 6 \mathrm{a} / \mathrm{b}$ on collective migration may be attributed to the direct interaction of $\mathrm{K} 6 \mathrm{a} / \mathrm{b}$ with myosin IIA [60]. In migrating $\mathrm{K} 6 \mathrm{a} / \mathrm{b}$ null keratinocytes, myosin IIA protein, but not mRNA, levels are decreased indicating that the keratin-myosin IIA interaction stabilizes myosin IIA to increase traction forces and slow down migration. Accordingly, larger FAs with a lower turnover are observed in $\mathrm{K} 6 \mathrm{a} / \mathrm{b}$ expressing cells [60]. However, the role of myosin IIA in keratinocyte migration is complex. Depleting myosin IIA does not affect keratinocyte migration, possibly due to a redundancy of other myosin isoforms. In fact, different pharmacological inhibitors that affect all myosin II isoforms, ML-7 (a myosin light chain kinase inhibitor) and blebbistatin (inhibitor of myosin II ATPase activity), have different effects on wild type and $\mathrm{K} 6 \mathrm{a} / \mathrm{b}$ null keratinocytes. As blebbistatin is able to solely inhibit migration of $\mathrm{K} 6 \mathrm{a} / \mathrm{b}$ null keratinocytes without affecting wild type cells, the enhanced migration potential is thought to depend on myosin II ATPase activity and increased contractility [60]. Together, results from these recent studies suggest that IFs regulate acto-myosin generated forces to optimize, i.e. promote or attenuate, collective migration by interacting with and modulating the force-generating machinery.

\section{IFs over control cell adhesions}

The actin cytoskeleton connects to adhesive structures, such as integrin-based FAs and cadherin-based AJs. FAs and AJs are regulated by acto-myosin cables that directly connect to these structures [61,62]. For instance, the association of stress fibers and increase ind acto-myosin contractility promote FA maturation and regulate FA turnover [63]. Accordingly, tension-dependent FA maturation, strength, size and turnover as well as changes in the dynamics of AJs may be regulated by the IF network through their influence on acto-myosin contractility $[4,6,47,64-67]$ (Figure 2). It is 
tempting to speculate that the loss of interjunctional actin arcs following depletion of vimentin, nestin and GFAP in astrocytes may beis responsible for AJ alterations observed in these cells as well [57].

However, adhesion molecules (integrins or cadherins) are engaged in intracellular signaling pathways that conversely regulate the actin-myosin network. This regulation enables the cell to adapt to the biochemical and mechanical properties of the environment of the cell. Thus, IFs can also modulate acto-myosin contractility via their interaction with adhesive structures (Figure 2). IFs interact with FAs via plectin (see [6], [23],[65] for detailed reviews on this interaction) (Figure 2B). Vimentin directly binds the tail of $\beta_{3^{-}}$[68] and $\alpha_{2} \beta_{1}$-integrins [69] (Figure 2B), and GFAP and vimentin interact with adhesion molecules such as vinculin and talin [57] (Figure 1A). In addition, IFs regulate the clustering and dynamics of integrins and the recruitment and activity of adhesion molecules involved in intracellular signaling, i.e. focal adhesion kinase (FAK) $[47,68,70-74]$ (Figure 2B). These the interactions of IFs with FAs can directly impact actinatignaling pathways and actin to regulate cell migration. Despite limited evidence, IFs might similarly affect the acto-myosin network by interacting with AJs.

The effects of IFs on FAs and AJs can also involve other integrin- and cadherin mediated adhesive structures to which IFs connect, hemidesmosomes and desmosomes. These epithelial structures are important to withstand mechanical stress and tension [4] (Figure 2A). Deletion of plectin, which disrupts the connection of IFs to hemidesmosomes, increases FAs and actin filaments $[65,75]$. This interplay between hemidesmosomal cell-matrix adhesions and FAs has recently been described in more detail in migrating keratinocytes [76] where keratin regulates the formation and localization of hemidesmosomes to attenuate cell migration and optimize re-epithelization [18]. In migrating keratinocytes, hemidesmosomes are distributed over the entire cell basal surface and are slightly enriched at the cell-border of leader cells in close proximity to FAs [76] (Figure 2A). Here, the hemidesmosomal components plectin and $\beta_{4}$-integrin align with keratin filaments in linear arrays. Disruption of these arrays following $\beta_{4}$-integrin depletion prevents hemidesmosome formation and promotes maturation of FAs, acto-myosin contraction ${ }_{2}$ and traction forces. Expression of $\beta_{4}$-integrin mutants and treatment with integrin-blocking antibodies have the same effect suggesting that the connection of $\beta_{4}$-integrins with the ECM and the IF network are both necessary for hemidesmosomes to control FA maturation [76]. The linear alignment of IFs in hemidesmosomes adjacent to FAs indicates that IFs are stretched and have taken up the energy generated by the uptake of energy by IEs which are stretched in response to-acto-myosin contractility. High linear keratins indeed correspond to the uptake of energy as has been shown by laser ablation of linear keratins in stretched cells [38]. Laser ablation of keratin in stretched cells leads to the rapid increase in the cell area which can be interpreted as a loss in tension and the release of energy [38]. Therefore, the ability of 
hemidesmosomes to reduce cell contractility and traction forces at FAs is likely to be achieved by the unique physical properties of IFs. Migration of the monolayer requires the disassembly of hemidesmosomes in leader cells. This results in a lower number of hemidesmosomes in leader cells compared to the trailing area of the migrating monolayer [76,77]; this may account for a balanced generation of traction forces to optimize migration. In tumor cells, the composition of hemidesmosomes is frequently altered [78]. This may-could result in an imbalance of traction forces that couldand be responsible for the inappropriate migratory behavior observed during EMT.

In epithelial lung cancer cells, vimentin and keratin are observed in close proximity to $\beta_{4^{-}}$ integrin-containing cell-matrix adhesions, reminiscent of hemidesmosomes (Figure 2B). Vimentin organizes in arrays near these adhesions [79], interacts with $\beta_{4}$-integrin via plectin [80] and increases the life-time of $\beta_{4}$-integrin puncta [79]. Theis interaction between $\beta_{4}$-integrin-containing adhesions and vimentin regulates Rac1 activity and recruitment to promote actin polymerization and directed cell migration [79]. This recent study supports the hypothesis that IFs regulate intracellular signaling at cell adhesions to control actin dynamics and cell migration.

IFs can also influence cellular forces via desmosomes [4,81-83]. IFs are tightly tethered to desmosomes mediated by desmoplakin which is important to maintain keratinocyte sheet integrity. During wound healing, desmosomes must progressively disassemble to enable cell migration and reform afterwards upon re-epithelization. Depletion of K6a/KGb disrupts desmosomes and increases the speed of migrating keratinocytes. This alters re-epithelization and renders the epithelial cell sheet fragile [60]. The increase in migration speed can be partially rescued by the overexpression of desmoplakin in $\mathrm{k} 6 \mathrm{a} / \mathrm{b}$ null keratinocytes. Desmoplakin overexpression may recruit other keratin proteins expressed in these cells and stabilize desmosomes. This suggests that IF-connected desmosomes are important to attenuate migration and optimize re-epithelization. As myosin IIA depletion has the same effect on cell-cell adhesions as the loss of $K 6 a / K G b$, the previously mentioned interaction between keratin 6 and myosin IIA might be key to this coordination. Keratin filaments may thus promote efficient wound closure through their interaction with myosin and the regulation of the actin cytoskeleton. Regardless of the contribution of other keratins, Fthe upregulation of $\mathrm{K} 6 \mathrm{a} / \mathrm{K} 6 \mathrm{~b}$ following injury seems essential to coordinate collective keratinocyte migration by stabilizing FAs and desmosome-mediated cell-cell adhesions (Figure 1B).

\section{IFs alleviate compressional forces exerted on the nucleus}

In most physiological conditions, cells migrate in a 3D environment and must navigate through tight constricted spaces. Cortical actin and microtubules align along substrate tracks and enhance migration speed when confinement, up to a threshold, is increased $[84,85]$. In contrast, recent studies show that 
vimentin attenuates the migration of cells through confined spaces and prevents the confinementinduced increase in migration speed $[85,86]$. In the absence of vimentin, increased confinement promotes migration speed in an actin and microtubule-dependent manner [85]. This suggests that vimentin counteracts the influence of actin and microtubules during confined migration [85]. As cells migrate through narrow spaces, the cells and their nuclei are subjected to compressive forces from surrounding tissues and vimentin is thought to have a protective role in this process (Figure 3 ). Classically, the nuclear lamina composed of lamin A/C and lamin B1 controls nuclear stiffness and protect the nucleus from damage [87]. However, the cytoplasmic vimentin IFs are needed for the stiff elastic response of the nucleus and thereby contribute to the mechanical homeostasis of the nucleus during confined migration [88]. Recent evidence shows that vimentin IFs organize into a cytoplasmic nuclear cage to protect the nucleus against compressive forces [86]. Depletion of vimentin in mouse embryonic fibroblasts (MEFs) leads to smaller and rounder nuclei with increased contour fluctuations. These fluctuations are indicative of decreased nuclear tension, which is supported by decreased cellular stiffness in regions above the nucleus $[85,86]$. Therefore, the ability of vimentin depleted cells to move faster through confined spaces might result from anincreased deformability of the nucleus. However, this occurs at the cost of increased DNA damage and necrosis as cells migrate through confined spaces (Figure 3), which is also observed upon axial compression in collagen gels [86]. The data suggest that vimentin has a primary role in maintaining nuclear integrity during confined migration by counteracting the strong actin-generated forces which tend to increase migration speed. This protective function of vimentin IFs may be related to their above-mentioned physical properties stiff elastic properties as observed in reconstituted IF networks. The $\forall$ vimentin IF network softens at low sare soft at low stress and strains $[37,39,89-91]$. Therefore, even if forces from cortical actomyosin are transmitted during cell adhesion to rigid surfaces, the vimentin network averages out these forces, and prevents large curvature deformations that can cause nuclear envelop ruptures. At higher stress and-strains, the stiffening of vimentin IFs enables them to dissipate energy and bear the large tensile loads generated by the compression of the environment and increased cytoskeletal contractility. Accordingly, vimentin polymerization increases in response to force application by stiff substrates [42] which may generate a more resilient perinuclear cage. These observations also suggest that the upregulation of vimentin during EMT may protect the nucleus from the high levels of mechanical stress, prevent cell death, and thus promote tumor cell invasion. However, the protection of the nucleus might be a cell-specific function of vimentin. In immune cells, which are specialized to migrate through the-confined spaces between endothelial cells, vimentin IFs localize towards the sides of adhesion to endothelial cells and do not appear to form a nuclear cage [92]. 


\section{Conclusion and perspectives}

Despite increasing efforts that show the contribution of IFs in single, collective and 3D migration, the exact mechanisms remain elusive. Current evidence points towards an antagonistic relationship between IFs and actin which is essential for optimal migration. In addition to their unique physical properties, Fthe interaction of IFs with the acto-myosin network, actin-associated adhesions, actomyosin upstream signaling pathways, (hemi-) desmosomes, and the nucleus provides IFs with the right equipment to steer and tame acto-myosin contractility. It is important to note that the net effects of IFs on cell migration depend on IF composition. Cytoplasmic vimentin and GFAP-containing IFs in astrocytes promote collective cell migration [57] while $\mathrm{K} 6 \mathrm{a} / \mathrm{b}$ IFs in keratinocytes attenuate migration [60]. Different keratins also play different roles. During epithelial wound healing, migration speed is attenuated as the expression of K6a/b, K16 and K17 increases and that of K1 and K10 decreases. In mesendoderm cells, K8 promotes collective migration [19], whereas in collectively invading breast cancer cells K14 depletion decreases metastasis [93]. Whether these differences result from specific intrinsic properties of the different keratin networks or from IF-type specific interactions with the actomyosin machinery remains unknown. Dependent on the cell type and mode of migration, IF network composition may be optimized to protect the cell and control the distribution of forces. This may explain the complex role of IFs in migration which either promote or attenuate migration speed.The cell-type specific expression of IFs and the diversity in IF-connections to adhesive structures and to the nucleus coordinate the organization of the IF network in such a way that forces are tempered or allowed where needed. Future studies should focus on these cell-type specific needs of force control by IFs and unravel the mechanisms by which IFs rule over actin during cell migration.

\section{Acknowledgments}

This work was supported by La Ligue contre le cancer. E.vB. was funded by the Fondation ARC pour la recherche sur le cancer. We would like to thank Shailaja Seetharaman for her critical reading of the manuscript and discussions. We apologize to authors whose work we were unable to discuss due to space constraints.

\section{Bibliography}

1. Etienne-Manneville S: Cytoplasmic Intermediate Filaments in Cell Biology. Annu Rev Cell Dev Biol 2018, 34.

2. Hol EM, Capetanaki Y: Type III Intermediate Filaments Desmin, Glial Fibrillary Acidic Protein (GFAP), Vimentin, and Peripherin. Cold Spring Harb Perspect Biol 2017, 9:a021642.

3. Schwarz N, Leube R: Intermediate Filaments as Organizers of Cellular Space: How They Affect Mitochondrial Structure and Function. Cells 2016, 5:30. 
4. Sanghvi-Shah R, Weber GF: Intermediate Filaments at the Junction of Mechanotransduction, Migration, and Development. Front Cell Dev Biol 2017, 5.

5. Battaglia RA, Delic S, Herrmann H, Snider NT: Vimentin on the move: new developments in cell migration. F1000Research 2018, 7.

6. Leduc C, Etienne-Manneville S: Intermediate filaments in cell migration and invasion: the unusual suspects. Curr Opin Cell Biol 2015, 32:102-112.

7. Yoon S, Leube RE: Keratin intermediate filaments: intermediaries of epithelial cell migration. Essays Biochem 2019, 63:521-533.

8. Carlier M-F, Pernier J, Montaville P, Shekhar S, Kühn S: Control of polarized assembly of actin filaments in cell motility. Cell Mol Life Sci 2015, 72:3051-3067.

9. Case LB, Waterman CM: Integration of actin dynamics and cell adhesion by a threedimensional, mechanosensitive molecular clutch. Nat Cell Biol 2015, 17:955-963.

10. Ladoux B, Mège R-M, Trepat X: Front-Rear Polarization by Mechanical Cues: From Single Cells to Tissues. Trends Cell Biol 2016, 26:420-433.

11. Leduc C, Etienne-Manneville S: Regulation of microtubule-associated motors drives intermediate filament network polarization. J Cell Biol 2017, 216:1689-1703.

12. Etienne-Manneville S: Microtubules in Cell Migration. Annu Rev Cell Dev Biol 2013, 29:471499.

13. Bance B, Seetharaman S, Leduc C, Boëda B, Etienne-Manneville S: Microtubule acetylation but not detyrosination promotes focal adhesion dynamics and astrocyte migration. J Cell Sci 2019, 132.

14. Bouchet BP, Akhmanova A: Microtubules in 3D cell motility. J Cell Sci 2017, 130:39-50.

15. Martin M, Veloso A, Wu J, Katrukha EA, Akhmanova A: Control of endothelial cell polarity and sprouting angiogenesis by non-centrosomal microtubules. eLife 2018, 7:e33864.

16. Mendez MG, Kojima SI, Goldman RD: Vimentin induces changes in cell shape, motility, and adhesion during the epithelial to mesenchymal transition. FASEB J 2010, 24:1838-1851.

17. Thiery JP, Acloque $H$, Huang RYJ, Nieto MA: Epithelial-Mesenchymal Transitions in Development and Disease. Cell 2009, 139:871-890.

18. Seltmann K, Roth W, Kröger C, Loschke F, Lederer M, Hüttelmaier S, Magin TM: Keratins Mediate Localization of Hemidesmosomes and Repress Cell Motility. J Invest Dermatol 2013, 133:181-190.

19. Sonavane PR, Wang C, Dzamba B, Weber GF, Periasamy A, DeSimone DW: Mechanical and signaling roles for keratin intermediate filaments in the assembly and morphogenesis of Xenopus mesendoderm tissue at gastrulation. Development 2017, 144:4363-4376.

20. Dupin I, Sakamoto Y, Etienne-Manneville S: Cytoplasmic intermediate filaments mediate actindriven positioning of the nucleus. J Cell Sci 2011, 124:865-872. 
21. Helfand BT, Mendez MG, Murthy SNP, Shumaker DK, Grin B, Mahammad S, Aebi U, Wedig T, $\mathrm{Wu} \mathrm{YI}, \mathrm{Hahn} \mathrm{KM}$, et al.: Vimentin organization modulates the formation of lamellipodia. $\mathrm{Mol}$ Biol Cell 2011, 22:1274-1289.

22. Eckes B, Dogic D, Colucci-Guyon E, Wang N, Maniotis A, Ingber D, Merckling A, Langa F, Aumailley $M$, Delouvée $A$, et al.: Impaired mechanical stability, migration and contractile capacity in vimentin-deficient fibroblasts. J Cell Sci 1998, 111 ( Pt 13):1897-1907.

23. Wiche G, Osmanagic-Myers S, Castañón MJ: Networking and anchoring through plectin: a key to IF functionality and mechanotransduction. Curr Opin Cell Biol 2015, 32:21-29.

24. Geerts D, Fontao L, Nievers MG, Schaapveld RQJ, Purkis PE, Wheeler GN, Lane EB, Leigh IM, Sonnenberg A: Binding of Integrin $\alpha 6 \beta 4$ to Plectin Prevents Plectin Association with F-Actin but Does Not Interfere with Intermediate Filament Binding. J Cell Biol 1999, 147:417-434.

25. Osmanagic-Myers S, Rus S, Wolfram M, Brunner D, Goldmann WH, Bonakdar N, Fischer I, Reipert S, Zuzuarregui $A$, Walko $G$, et al.: Plectin reinforces vascular integrity by mediating crosstalk between the vimentin and the actin networks. J Cell Sci 2015, 128:4138-4150.

26. Svitkina TM, Verkhovsky AB, Borisy GG: Plectin sidearms mediate interaction of intermediate filaments with microtubules and other components of the cytoskeleton. J Cell Biol 1996, 135:991-1007.

27. Huber F, Boire A, López MP, Koenderink GH: Cytoskeletal crosstalk: when three different personalities team up. Curr Opin Cell Biol 2015, 32:39-47.

28. Dogterom M, Koenderink GH: Actin-microtubule crosstalk in cell biology. Nat Rev Mol Cell Biol 2019, 20:38-54.

29. Gan Z, Ding L, Burckhardt CJ, Lowery J, Zaritsky A, Sitterley K, Mota A, Costigliola N, Starker CG, Voytas DF, et al.: Vimentin Intermediate Filaments Template Microtubule Networks to Enhance Persistence in Cell Polarity and Directed Migration. Cell Syst 2016, 3:252-263.e8.

30. Sakamoto Y, Boëda B, Etienne-Manneville S: APC binds intermediate filaments and is required for their reorganization during cell migration. J Cell Biol 2013, 200:249-258.

31. Cheng $F$, Shen $Y$, Mohanasundaram $P$, Lindström $M$, Ivaska J, Ny T, Eriksson JE: Vimentin coordinates fibroblast proliferation and keratinocyte differentiation in wound healing via TGF-ß $\beta$-Slug signaling. Proc Natl Acad Sci U S A 2016, 113:E4320-4327.

32. Block J, Schroeder V, Pawelzyk P, Willenbacher N, Köster S: Physical properties of cytoplasmic intermediate filaments. Biochim Biophys Acta 2015, 1853:3053-3064.

33. Kreplak L, Bär H, Leterrier JF, Herrmann H, Aebi U: Exploring the Mechanical Behavior of Single Intermediate Filaments. J Mol Biol 2005, 354:569-577.

34. Block J, Witt H, Candelli A, Peterman EJG, Wuite GJL, Janshoff A, Köster S: Nonlinear LoadingRate-Dependent Force Response of Individual Vimentin Intermediate Filaments to Applied Strain. Phys Rev Lett 2017, 118:048101.

35. Lorenz C, Forsting J, Schepers AV, Kraxner J, Bauch S, Witt H, Klumpp S, Köster S: Lateral Subunit Coupling Determines Intermediate Filament Mechanics. Phys Rev Lett 2019, 123:188102. 
36. Block J, Witt H, Candelli A, Danes JC, Peterman EJG, Wuite GJL, Janshoff A, Köster S: Viscoelastic properties of vimentin originate from nonequilibrium conformational changes. Sci Adv 2018, 4:eaat1161.

37. Golde T, Huster C, Glaser M, Händler T, Herrmann H, Käs JA, Schnauß J: Glassy dynamics in composite biopolymer networks. Soft Matter 2018, 14:7970-7978.

*The mechanical properties of the composite networks reconstituted from actin and vimentin can be exptrapolated from their respective non-interacting substructures. In contrast to previous studies, no emergent characteristics of the composite network are observed when the mesh size of the network, i.e. the average space between neighboring filaments, is kept constant. The mechanical properties of composite networks with different levels of vimentin and actin but a constant mesh size vary in between the extremes of pure actin and vimentin networks.

38. Latorre E, Kale S, Casares L, Gómez-González M, Uroz M, Valon L, Nair RV, Garreta E, Montserrat N, del Campo A, et al.: Active superelasticity in three-dimensional epithelia of controlled shape. Nature 2018, 563:203-208.

*A type of mechanical behavior needed for the epithelial sheet to withstand extreme threedimensional deformations under constant tension is identified in a 3D model of the epithelial sheet: superelasticty. Superelasticity of the cell requires strain-softening at low strains and re-stiffening at large strains. The authors show that strain-softening is achieved by the dilution of the actin cortex, and re-stiffening by intermediate filaments that are able to bear large tensile loads.

39. Hu J, Li Y, Hao Y, Zheng T, Gupta SK, Parada GA, Wu H, Lin S, Wang S, Zhao X, et al.: High stretchability, strength, and toughness of living cells enabled by hyperelastic vimentin intermediate filaments. Proc Natl Acad Sci 2019, 116:17175-17180.

* The VIF network forms a stretchable, hyperelastic network in living cells that is essential to maintain resilience of the cytoplasm upon large deformations of the cell. The VIF network can propagate local deformations to a larger region of the cell to reduce the risk of cell damage.

40. Nolting J-F, Köster S: Influence of microfluidic shear on keratin networks in living cells. New J Phys 2013, 15:045025.

41. Weber GF, Bjerke MA, DeSimone DW: A Mechanoresponsive Cadherin-Keratin Complex Directs Polarized Protrusive Behavior and Collective Cell Migration. Dev Cell 2012, 22:104115.

42. Murray ME, Mendez MG, Janmey PA: Substrate stiffness regulates solubility of cellular vimentin. Mol Biol Cell 2014, 25:87-94.

43. Guo M, Ehrlicher AJ, Mahammad S, Fabich H, Jensen MH, Moore JR, Fredberg JJ, Goldman RD, Weitz DA: The Role of Vimentin Intermediate Filaments in Cortical and Cytoplasmic Mechanics. Biophys J 2013, 105:1562-1568.

44. Jiu Y, Lehtimäki J, Tojkander S, Cheng F, Jäälinoja H, Liu X, Varjosalo M, Eriksson JE, Lappalainen P: Bidirectional Interplay between Vimentin Intermediate Filaments and Contractile Actin Stress Fibers. Cell Rep 2015, 11:1511-1518.

45. Costigliola N, Ding L, Burckhardt CJ, Han SJ, Gutierrez E, Mota A, Groisman A, Mitchison TJ, Danuser G: Vimentin fibers orient traction stress. Proc Natl Acad Sci U S A 2017, 114:51955200. 
46. Esue O, Carson AA, Tseng Y, Wirtz D: A Direct Interaction between Actin and Vimentin Filaments Mediated by the Tail Domain of Vimentin. J Biol Chem 2006, 281:30393-30399.

47. Gregor M, Osmanagic-Myers S, Burgstaller G, Wolfram M, Fischer I, Walko G, Resch GP, Jörgl A, Herrmann $\mathrm{H}$, Wiche $\mathrm{G}$ : Mechanosensing through focal adhesion-anchored intermediate filaments. FASEB J 2014, 28:715-729.

48. Jiu Y, Peränen J, Schaible N, Cheng F, Eriksson JE, Krishnan R, Lappalainen P: Vimentin intermediate filaments control actin stress fiber assembly through GEF-H1 and RhoA. J Cell Sci 2017, 130:892-902.

49. Fujiwara S, Ohashi K, Mashiko T, Kondo H, Mizuno K: Interplay between Solo and keratin filaments is crucial for mechanical force-induced stress fiber reinforcement. Mol Biol Cell 2016, 27:954-966.

50. Peglion $\mathrm{F}$, Llense $\mathrm{F}$, Etienne-Manneville $\mathrm{S}$ : Adherens junction treadmilling during collective migration. Nat Cell Biol 2014, 16:639-651.

51. Hu S, Dasbiswas K, Guo Z, Tee Y-H, Thiagarajan V, Hersen P, Chew T-L, Safran SA, Zaidel-Bar R, Bershadsky AD: Long-range self-organization of cytoskeletal myosin II filament stacks. Nat Cell Biol 2017, 19:133-141.

52. Burnette DT, Manley S, Sengupta P, Sougrat R, Davidson MW, Kachar B, Lippincott-Schwartz J: A role for actin arcs in the leading-edge advance of migrating cells. Nat Cell Biol 2011, 13:371382.

53. du Roure O, Saez A, Buguin A, Austin RH, Chavrier P, Silberzan P, Siberzan P, Ladoux B: Force mapping in epithelial cell migration. Proc Natl Acad Sci U S A 2005, 102:2390-2395.

54. Trepat X, Wasserman MR, Angelini TE, Millet E, Weitz DA, Butler JP, Fredberg JJ: Physical forces during collective cell migration. Nat Phys 2009, 5:426-430.

55. Tambe DT, Hardin CC, Angelini TE, Rajendran K, Park CY, Serra-Picamal X, Zhou EH, Zaman MH, Butler JP, Weitz DA, et al.: Collective cell guidance by cooperative intercellular forces. Nat Mater 2011, 10:469-475.

56. Serra-Picamal X, Conte V, Sunyer R, Muñoz JJ, Trepat X: Mapping forces and kinematics during collective cell migration. Methods Cell Biol 2015, 125:309-330.

57. De Pascalis C, Pérez-González C, Seetharaman S, Boëda B, Vianay B, Burute M, Leduc C, Borghi $\mathrm{N}$, Trepat $\mathrm{X}$, Etienne-Manneville $\mathrm{S}$ : Intermediate filaments control collective migration by restricting traction forces and sustaining cell-cell contacts. J Cell Biol 2018, doi:10.1083/jcb.201801162.

**IF depletion in collectively migrating astrocytes reduces migration speed and changes the organization and dynamics of the acto-myosin network, of focal adhesions, and of adherence junctions. Together with the cytoskeletal linker plectin, IFs restrict the generation of traction forces to the front of leader cells and maintain cell-cell interactions to optimize migration.

58. Wong P, Colucci-Guyon E, Takahashi K, Gu C, Babinet C, Coulombe PA: Introducing a null mutation in the mouse K6alpha and K6beta genes reveals their essential structural role in the oral mucosa. J Cell Biol 2000, 150:921-928. 
59. Wong $P$, Coulombe PA: Loss of keratin 6 (K6) proteins reveals a function for intermediate filaments during wound repair. J Cell Biol 2003, 163:327-337.

60. Wang F, Chen S, Liu HB, Parent CA, Coulombe PA: Keratin 6 regulates collective keratinocyte migration by altering cell-cell and cell-matrix adhesion. J Cell Biol 2018, 217:4314-4330.

**Keratin 6 depletion enhances cell migration speed and directionality in a cell-autonomous and ECM dependent manner, increases focal adhesion disassembly rates and decreases cell-cell adhesions. A new interaction between keratin 6 and myosin IIA is reported.

61. Maruthamuthu V, Aratyn-Schaus Y, Gardel ML: Conserved F-actin dynamics and force transmission at cell adhesions. Curr Opin Cell Biol 2010, 22:583-588.

62. Bachir Al, Horwitz AR, Nelson WJ, Bianchini JM: Actin-Based Adhesion Modules Mediate Cell Interactions with the Extracellular Matrix and Neighboring Cells. Cold Spring Harb Perspect Biol 2017, 9:a023234.

63. Geiger B, Bershadsky A, Pankov R, Yamada KM: Transmembrane crosstalk between the extracellular matrix--cytoskeleton crosstalk. Nat Rev Mol Cell Biol 2001, 2:793-805.

64. Tsuruta D, Jones JCR: The vimentin cytoskeleton regulates focal contact size and adhesion of endothelial cells subjected to shear stress. J Cell Sci 2003, 116:4977-4984.

65. Leube RE, Moch M, Windoffer R: Intermediate filaments and the regulation of focal adhesion. Curr Opin Cell Biol 2015, 32:13-20.

66. Bhattacharya R, Gonzalez AM, DeBiase PJ, Trejo HE, Goldman RD, Flitney FW, Jones JCR: Recruitment of vimentin to the cell surface by 3 integrin and plectin mediates adhesion strength. J Cell Sci 2009, 122:1390-1400.

67. Liu C-Y, Lin H-H, Tang M-J, Wang Y-K: Vimentin contributes to epithelial-mesenchymal transition cancer cell mechanics by mediating cytoskeletal organization and focal adhesion maturation. Oncotarget 2015, 6.

68. Kim J, Yang C, Kim EJ, Jang J, Kim S-J, Kang SM, Kim MG, Jung H, Park D, Kim C: Vimentin filaments regulate integrin-ligand interactions by binding to the cytoplasmic tail of integrin B3. J Cell Sci 2016, 129:2030-2042.

69. Kreis S, Schönfeld H-J, Melchior C, Steiner B, Kieffer N: The intermediate filament protein vimentin binds specifically to a recombinant integrin alpha2/beta1 cytoplasmic tail complex and co-localizes with native alpha2/beta1 in endothelial cell focal adhesions. Exp Cell Res 2005, 305:110-121.

70. Hyder CL, Lazaro G, Pylvänäinen JW, Roberts MWG, Qvarnström SM, Eriksson JE: Nestin regulates prostate cancer cell invasion by influencing the localisation and functions of FAK and integrins. J Cell Sci 2014, 127:2161-2173.

71. Rotty JD, Coulombe PA: A wound-induced keratin inhibits Src activity during keratinocyte migration and tissue repair. J Cell Biol 2012, 197:381-389.

72. Bordeleau F, Galarneau L, Gilbert S, Loranger A, Marceau N: Keratin 8/18 modulation of protein kinase C-mediated integrin-dependent adhesion and migration of liver epithelial cells. Mol Biol Cell 2010, 21:1698-1713. 
73. Ivaska J, Vuoriluoto K, Huovinen T, Izawa I, Inagaki M, Parker PJ: PKCE-mediated phosphorylation of vimentin controls integrin recycling and motility. EMBO J 2005, 24:38343845 .

74. Havel LS, Kline ER, Salgueiro AM, Marcus AI: Vimentin regulates lung cancer cell adhesion through a VAV2-Rac1 pathway to control focal adhesion kinase activity. Oncogene 2015, 34:1979-1990.

75. Andra K, Nikolic B, Stocher M, Drenckhahn D, Wiche G: Not just scaffolding: plectin regulates actin dynamics in cultured cells. Genes Dev 1998, 12:3442-3451.

76. Wang W, Zuidema A, te Molder L, Nahidiazar L, Hoekman L, Schmidt T, Coppola S, Sonnenberg A: Hemidesmosomes modulate force generation via focal adhesions. J Cell Biol 2020, 219:e201904137.

**This paper describes how IF-connected hemidesmosomal integrin $\alpha 6 \beta 4$ impacts the maturation of focal adhesions, traction forces, and mechanoresponsive signaling pathways.

77. Hopkinson SB, Hamill KJ, Wu Y, Eisenberg JL, Hiroyasu S, Jones JCR: Focal Contact and Hemidesmosomal Proteins in Keratinocyte Migration and Wound Repair. Adv Wound Care 2014, 3:247-263.

78. Stewart RL, $\mathrm{O}^{\prime}$ Connor $\mathrm{KL}$ : Clinical significance of the integrin $\alpha 6 \beta 4$ in human malignancies. Lab Invest 2015, 95:976-986.

79. Colburn $\mathrm{ZT}$, Jones JCR: Complexes of $\alpha 6 \beta 4$ integrin and vimentin act as signaling hubs to regulate epithelial cell migration. J Cell Sci 2018, 131:jcs214593.

**Vimentin binds $\beta 4$ integrin via plectin and regulates $\beta 4$ integrin dynamics. Vimentin depletion reduces directed migration, Rac1 activity and Rac1 recruitment at $\alpha 6 \beta 4$-integrin clusters indicating that $\beta 4$-integrin and vimentin act as signaling hubs to regulate cell motility.

80. Homan S: Regulation of the Association of $\alpha 6 \beta 4$ with Vimentin Intermediate Filaments in Endothelial Cells. Exp Cell Res 2002, 281:107-114.

81. Broussard JA, Yang R, Huang C, Nathamgari SSP, Beese AM, Godsel LM, Hegazy MH, Lee S, Zhou $\mathrm{F}$, Sniadecki NJ, et al.: The desmoplakin-intermediate filament linkage regulates cell mechanics. Mol Biol Cell 2017, 28:3156-3164.

82. Green KJ, Jaiganesh A, Broussard JA: Desmosomes: Essential contributors to an integrated intercellular junction network. F1000Research 2019, 8.

83. Moch M, Schwarz N, Windoffer R, Leube RE: The keratin-desmosome scaffold: pivotal role of desmosomes for keratin network morphogenesis. Cell Mol Life Sci 2019, doi:10.1007/s00018019-03198-y.

* Keratin 8 proteins cluster at newly formed desmosomes. This is followed by the formation of keratin filaments, filament elongation, and the generation of a stable keratin network. Desmosomes are identified as the organizing centers of the keratin cytoskeleton.

84. Liu Y-J, Le Berre M, Lautenschlaeger F, Maiuri P, Callan-Jones A, Heuzé M, Takaki T, Voituriez R, Piel M: Confinement and Low Adhesion Induce Fast Amoeboid Migration of Slow Mesenchymal Cells. Cell 2015, 160:659-672. 
85. Patteson AE, Pogoda K, Byfield FJ, Mandal K, Ostrowska-Podhorodecka Z, Charrier EE, Galie PA, Deptuła P, Bucki R, McCulloch CA, et al.: Loss of Vimentin Enhances Cell Motility through Small Confining Spaces. Small 2019, 15:1903180.

** The loss of vimentin increases cell motility in 3D microchannels and decreases perinuclear stiffness. A minimal model is proposed in which the vimentin perinuclear cage is constricted along with the nucleus when the cell moves through constricted spaces and provides mechanical resistance at strains that could affect nuclear integrity.

86. Patteson AE, Vahabikashi A, Pogoda K, Adam SA, Mandal K, Kittisopikul M, Sivagurunathan S, Goldman A, Goldman RD, Janmey PA: Vimentin protects cells against nuclear rupture and DNA damage during migration. J Cell Biol 2019, 218:4079-4092.

**The loss of vimentin affects nuclear size, shape and perinuclear stiffness and increases motility through confined spaces. This happens at the cost of increased nuclear rupture and DNA damage upon confinement that can be rescued by the re-expression of vimentin.

87. McGregor AL, Hsia C-R, Lammerding J: Squish and squeeze - the nucleus as a physical barrier during migration in confined environments. Curr Opin Cell Biol 2016, 40:32-40.

88. Neelam S, Chancellor TJ, Li Y, Nickerson JA, Roux KJ, Dickinson RB, Lele TP: Direct force probe reveals the mechanics of nuclear homeostasis in the mammalian cell. Proc Natl Acad Sci 2015, 112:5720-5725.

89. Herrmann H, Bär H, Kreplak L, Strelkov SV, Aebi U: Intermediate filaments: from cell architecture to nanomechanics. Nat Rev Mol Cell Biol 2007, 8:562-573.

90. Mendez MG, Restle D, Janmey PA: Vimentin Enhances Cell Elastic Behavior and Protects against Compressive Stress. Biophys J 2014, 107:314-323.

91. Janmey PA, Euteneuer U, Traub P, Schliwa M: Viscoelastic properties of vimentin compared with other filamentous biopolymer networks. J Cell Biol 1991, 113:155-160.

92. Nieminen $M$, Henttinen $T$, Merinen $M$, Marttila-Ichihara F, Eriksson JE, Jalkanen S: Vimentin function in lymphocyte adhesion and transcellular migration. Nat Cell Biol 2006, 8:156-162.

93. Cheung KJ, Padmanaban V, Silvestri V, Schipper K, Cohen JD, Fairchild AN, Gorin MA, Verdone $\mathrm{JE}$, Pienta KJ, Bader JS, et al.: Polyclonal breast cancer metastases arise from collective dissemination of keratin 14-expressing tumor cell clusters. Proc Natl Acad Sci 2016, 113:E854E863.

\section{Figure 1 IF-control over actomyosin optimizes collective cell migration}

IFs regulate and interact with the acto-myosin machinery in collectively migrating astrocytes $(A)$ and keratinocytes (B). A. Depletion of IFs (GFAP, vimentin and nestin) in collectively migrating astrocytes increases longitudinal stress fibers and decreases interjunctional transverse $\operatorname{arcs}(A$, right). Larger focal adhesionFAs and a longer lifetime, discontinuous cell-cell adhesions, and increased -traction forces within the migrating monolayer contribute to the loss of collective migration speed and directionality $(A$, left). These alterations can result from a direct interaction of GFAP and vimentin with the acto- 
myosin machinery via the cytoskeletal linker plectin (box 2) and/or with focaldhesionFA and adherens junctionAJ components vinculin and talin (box 1). B. Depletion of keratin 6a and 6b (K6) decreases focal adhesionFA size and lifetime and decreases cell-cell adhesions via desmosomes ( $B$, left). This increases migration speed at the cost of integrity of the re-epithelialized sheet. The interaction between $\mathrm{K} 6$ and myosin IIA (box 3) is hypothesized to play an important role in the attenuation of collective keratinocyte migration.

\section{Figure 2 The IF-actomyosin interaction via cell-matrix adhesions}

A. The interplay between IF-connected hemidesmosomes (HDS) and actomyosin-connected focal adhesions in keratin-expressing epithelial cells. In the presence of hemidesmosomes traction forces exerted at focal adhesions are lower. Near these focal adhesions, keratin IFs align in linear arrays (box 1). Disassembly of hemidesmosomesHDs, or disconnection of IFs from HDshemidesmosomes, increases focal adhesion size and number, and traction forces. These changes could result from a direct interaction between hemidesmosomes $\mathrm{HB}$ and FAs (dotted arrow), or result from the interplay between IFs, FAs and acto-myosin (arrows). B. The interplay between IF-connected cell-matrix adhesions, FAs, and acto-myosin upstream signaling. In vimentin-expressing epithelial cancer cells, cell-matrix adhesions reminiscent of hemidesmosomes are linked to the IF-network via an $\alpha 6 \beta 4$ plectin-vimentin interaction (box 2). Vimentin that organizes in linear arrays at these adhesions interacts with, and regulates the dynamics of, $\beta 4$ integrin and activity of the RhoA-GEF Rac1 that promotes actin polymerization. In the absence of vimentin (B, bottom), Rac1 activity, focaladhesionFA numbers, and cell motility are decreased. Vimentin can regulate FAs and actomyosin via Viza direct interaction with for example $\beta 1$-integrin, via plectin ${ }_{L}$ or via downstream integrin signaling_vimentin ean regulate FAs and actomyosin-as well (box 3). Arrows indicate how IFs, actomyosin and cell-matrix adhesions are connected in an integrated system.

\section{Figure 3 The IF nuclear cage protects the nucleus during confined migration.}

Confined 3D migration through tight constricted spaces requires actin polymerization at the cell front (protrusive forces), acto-myosin contractility (contractile forces) for rear retraction, and cell squeezing and deformation (compressive forces). Vimentin IFs form a nuclear cage around the nucleus that slows down migration through confined spaces (top). Vimentin depletion increases confined migration (bottom) but induces DNA damage, nuclear blebbing and cell death. Vimentin IFs form a nuclear cage that protects the nucleus from forces induced by the environment and by -strong acto-myosin contractility during confined 3D migration. 


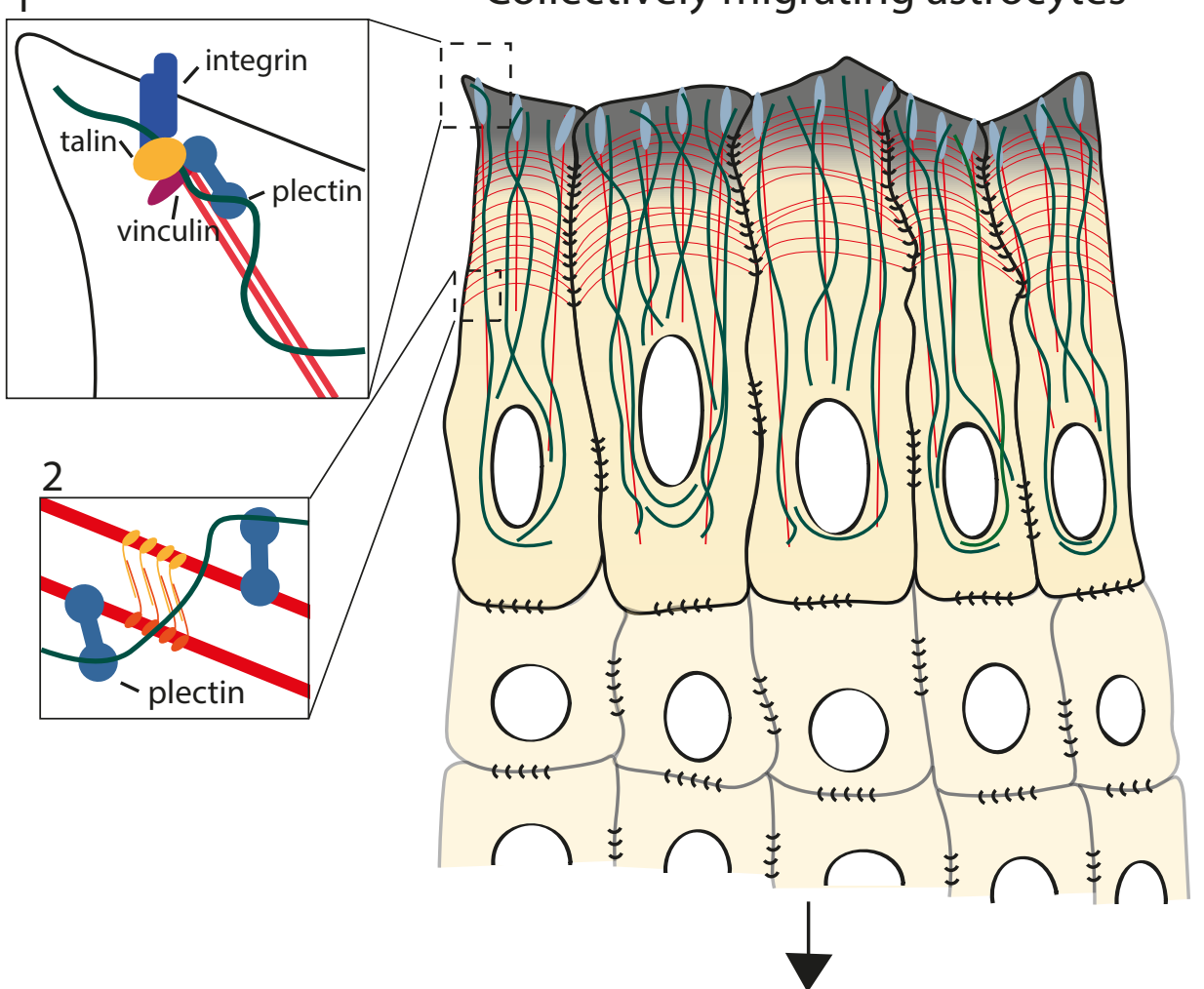

GFAP, vimentin, nestin IF depletion
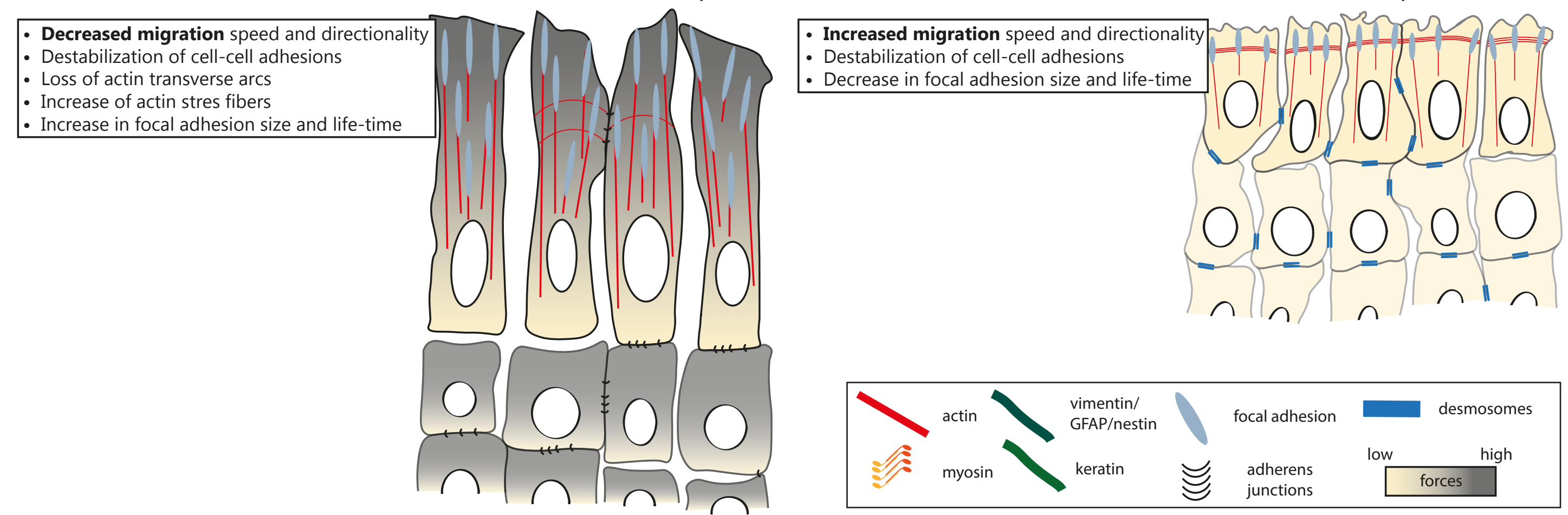

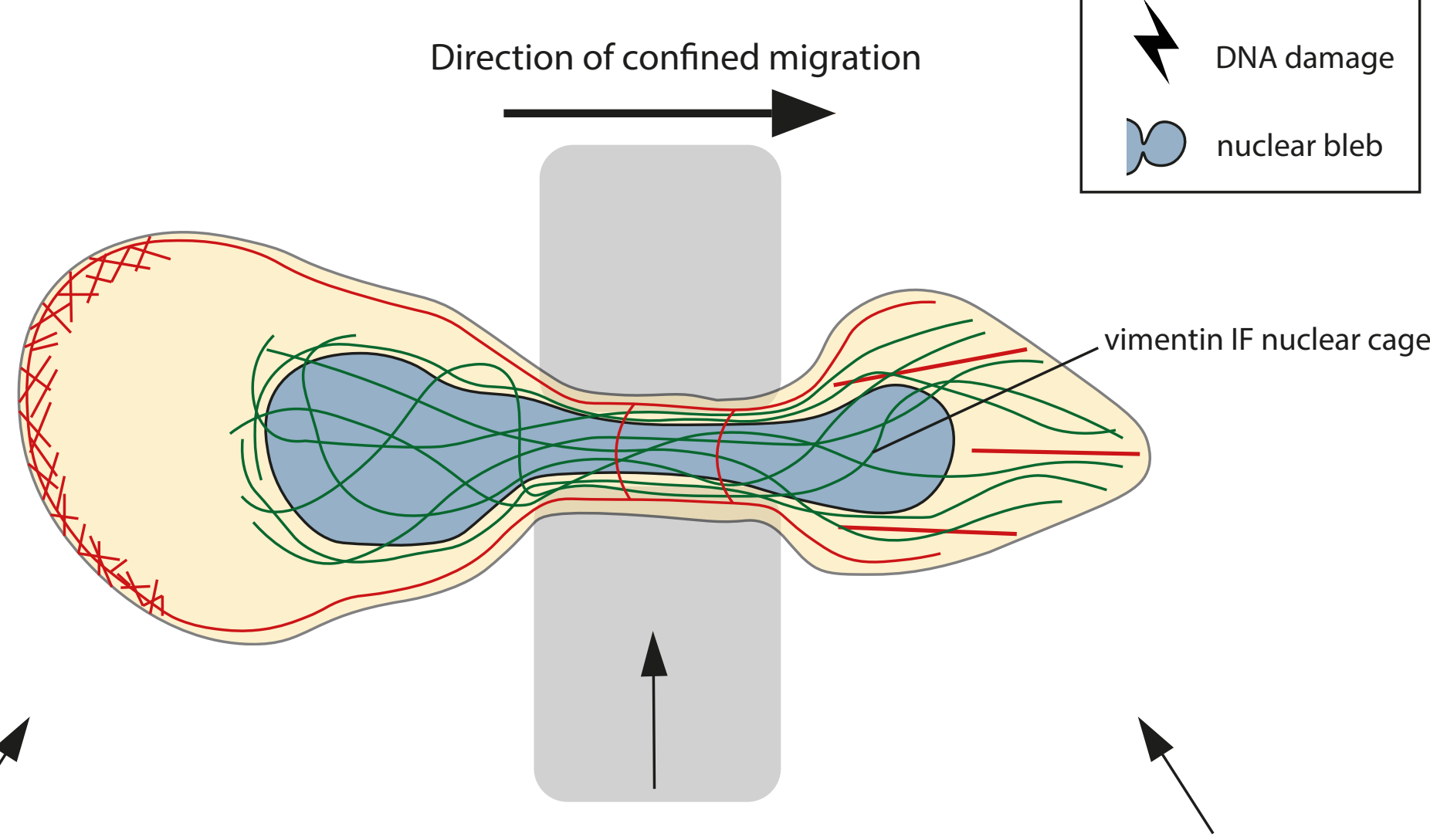

contractile forces compressive forces

protrusive forces

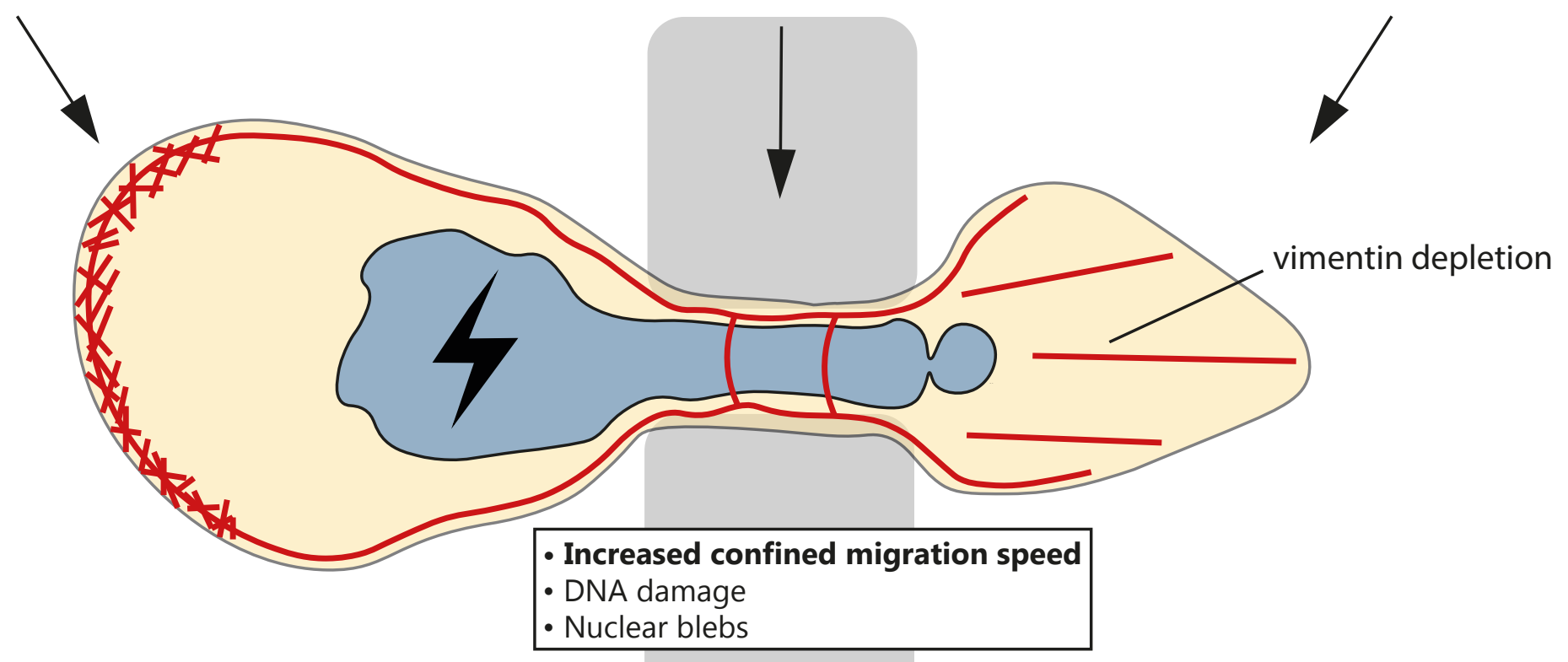




\section{$\phi$}

I NSTITUT PASTEUR

Paris, le 15/02/20

Cell Polarity, Migration

and Cancer Unit

Institut Pasteur

25 rue du Dr Roux, 75724 Paris cedex 15

FRANCE

De : Etienne-Manneville Sandrine

Telephone: 0140613905

FAX: $\quad 0145688548$

E-mail : setienne@pasteur.fr

O B J E T : Conflict of Interest

I and the authors declare no conflict of interest

Sandrine Etienne-Manneville, Emma van Bodegraven

कrenke

Sandrine Etienne-Manneville, $\mathrm{PhD}$ 